\title{
Características produtivas de cordeiros terminados em confinamento com dietas contendo diferentes teores de borra de soja
}

\author{
[Productive characteristics of lambs finished in feedlot fed different levels \\ of soybean soapstock] \\ S. Carvalho ${ }^{1}$, C.C. Pires ${ }^{1,4}$, S. Macari ${ }^{2}$, J.F. Lopes $^{4}$, A.B. Moro ${ }^{3}$, R.S. Venturini ${ }^{3}$, \\ A. Lins $^{3}$, R.S. Teixeira ${ }^{3}$ \\ ${ }^{1}$ Universidade Federal de Santa Maria - Santa Maria, RS \\ ${ }^{2}$ Pós-doutorando (PNPD-Capes) - Universidade Federal de Santa Maria - Santa Maria, RS \\ ${ }^{3}$ Aluno de graduação - Universidade Federal de Santa Maria - Santa Maria, RS \\ ${ }^{4}$ Bolsista de Produtividade - PQ/CNPq-Nível 2
}

\section{RESUMO}

\begin{abstract}
Avaliou-se o efeito de dietas contendo diferentes teores de borra de soja sobre o consumo de nutrientes, o ganho de peso, as características de carcaça e os componentes do peso vivo de cordeiros terminados em confinamento. Foram utilizados 25 cordeiros, machos, castrados, da raça Texel, distribuídos aleatoriamente em cinco tratamentos compostos por proporções de $0 \%, 2,89 \%, 5,77 \%, 8,65 \%$ ou $11,55 \%$ de borra de soja na matéria seca das dietas. Houve redução linear do consumo de nutrientes, com exceção do consumo de extrato etéreo, que aumentou linearmente. O peso vivo ao abate, o ganho de peso diário, os pesos e rendimentos de carcaça quente e fria, e os pesos de perna e de costilhar diminuíram linearmente, ao passo que as proporções de rúmen e do trato gastrintestinal, com conteúdo, bem como o conteúdo gastrointestinal, aumentaram linearmente com o aumento dos níveis de borra de soja nas dietas. A proporção de perna foi influenciada de forma quadrática. O aumento da participação de borra de soja na dieta de cordeiros em sistema de confinamento leva à diminuição do desempenho produtivo dos animais. Contudo, o lucro diário obtido por animal não é influenciado, podendo-se inferir que a inclusão de borra de soja até o nível de $11,55 \%$ da matéria seca total da dieta é uma alternativa viável para a terminação de cordeiros em confinamento.
\end{abstract}

Palavras-chave: ovino, carcaça, carne

\begin{abstract}
We evaluated the nutrient intake, weight gain, carcass characteristics and the non carcass components of lambs in feedlot finishing diets containing increasing levels of soybean soapstock. We used 25 male lambs, castrated Texel, randomly distributed into five treatments consisting of proportions of 0\%, 2.89\%, $5.77 \%, 8.65 \%$ or $11.55 \%$ of soybean soapstock in the dry matter this diets. Linear reduction of nutrient intake was observed, with the exception of the consumption of ether extract, which increased linearly. The live weight at slaughter, the daily weight gain, the weights and yields from hot and cold carcass and the weights of hindquarter and rib decreased linearly, while the proportions of rumen and gastrointestinal tract, full and gastrointestinal tract content increased in a linear way as it increased the proportion of level this soybean soapstock in the diet. The proportion of hindquarter varied in a quadratic way. The increase in soybean soapstock in the diet of lambs in confinement system leads to decrease in productive performance of animals. However, the daily profit obtained per animal is not affected, and we may infer that the inclusion of soybean soapstock to the level of $11.55 \%$ of the total dry matter of the diet is a viable alternative to termination of feedlot lambs.
\end{abstract}

Keywords: sheep, carcass, meat

Recebido em 21 de agosto de 2012

Aceito em 30 de julho de 2013

E-mail: scarvalhoufsm@hotmail.com 


\section{INTRODUÇÃO}

Atualmente, a principal finalidade da ovinocultura brasileira é a produção de carne, mas o mercado tem sido prejudicado pela falta de regularidade da oferta desse produto. Além disso, grande parte dos animais destinados ao abate são criados em pastagens nativas, onde, segundo Neres et al. (2001), dificilmente obtém-se boa produtividade e qualidade de carne ovina, devido à deficiência da ingestão de nutrientes, havendo a necessidade da utilização de sistemas mais intensivos de produção, como o confinamento, para explorar o máximo potencial genético dos animais.

A alimentação de cordeiros em confinamento possibilita a terminação de ovinos em períodos de carência alimentar ou quando as pastagens ainda não estejam prontas, além de poder disponibilizar, no mercado, carne ovina de qualidade no período de entressafra. Conforme Madruga et al. (2005), a terminação em confinamento com alimentação de alto valor nutritivo constitui-se uma prioridade quando o sistema de produção visa atingir níveis elevados de ganho de peso.

O conhecimento do valor nutritivo dos alimentos é um fator importante do sistema de confinamento. Segundo Oliveira et al. (2002), a alimentação é o item que mais onera a terminação de cordeiros em confinamento, levando à busca por ingredientes mais baratos, buscando viabilizar a adoção desse sistema de produção. Brochier e Carvalho (2008) afirmam que o uso de subprodutos agroindustriais na alimentação animal assume papel econômico muito importante, sendo, muitas vezes, responsável pela viabilidade econômica do sistema.

O processamento agroindustrial da soja gera um resíduo denominado borra de soja, uma fonte de gordura que surge como uma alternativa interessante para redução dos custos de alimentação da terminação de cordeiros. No entanto, a inclusão de altos teores de gordura na alimentação de ruminantes pode comprometer o desempenho dos animais devido à redução da digestibilidade e da palatabilidade dos alimentos, em decorrência do efeito tóxico dos ácidos graxos de cadeia longa sobre as bactérias ruminais (Johnson e Mclure, 1973; Gibb et al., 2005).

Devido às escassas informações sobre o uso da borra de soja na dieta de ovinos, o objetivo deste trabalho foi avaliar o consumo de nutrientes, o ganho de peso, as características de carcaça e dos componentes do peso vivo, exceto a carcaça, de cordeiros terminados em confinamento com dietas contendo teores crescentes de borra de soja.

\section{MATERIAL E MÉTODOS}

O experimento foi conduzido no Laboratório de Ovinocultura do Departamento de Zootecnia da Universidade Federal de Santa Maria, localizado na cidade de Santa Maria, Rio Grande do Sul. O período experimental estendeu-se de 17 de novembro de 2009 a 19 de janeiro de 2010.

Foram utilizados 25 cordeiros, machos castrados, da raça Texel, distribuídos aleatoriamente em cinco tratamentos compostos por diferentes teores de borra de soja incluídos na dieta como parte da matéria seca total, sendo: $0 \% ; 2,89 \%$; $5,77 \% ; 8,65 \%$ ou $11,55 \%$.

Os animais foram alojados em baias individuais, providas de comedouros e bebedouros. Os cordeiros foram pesados no início e final do experimento e a cada 14 dias, após jejum de sólidos e líquidos de 14 horas. As dietas experimentais foram fornecidas duas vezes ao dia, ad libitum, com relação volumoso:concentrado de 40:60, com base na matéria seca (MS). O volumoso utilizado foi o feno de aveia, previamente moído em triturador, e os concentrados eram compostos por fubá de milho, farelo de soja, calcário calcítico e sal comum, com adição crescente de borra de soja, de acordo com os tratamentos. As dietas foram formuladas para serem isoproteicas, de acordo com a exigência preconizada pela NRC (National..., 1985), para ganho de $250 \mathrm{~g}$ diários. $\mathrm{Na}$ Tabela 1 é apresentada a composição bromatológica dos alimentos utilizados na formulação das dietas e, na Tabela 2, a proporção dos ingredientes e a composição bromatológica das dietas experimentais. 
Tabela 1. Teores médios de matéria seca (MS), matéria orgânica (MO), proteína bruta (PB), extrato etéreo (EE), fibra em detergente neutro (FDN), fibra em detergente ácido (FDA), carboidratos totais (CHT), carboidratos não estruturais (CNE), cinzas (CIN), energia líquida (EL), cálcio (Ca) e fósforo (P) dos ingredientes utilizados na formulação das dietas experimentais

\begin{tabular}{|c|c|c|c|c|c|c|}
\hline Item (\%) & $\begin{array}{l}\text { Feno } \\
\text { Aveia }\end{array}$ & $\begin{array}{c}\text { Fubá } \\
\text { de milho }\end{array}$ & $\begin{array}{l}\text { Farelo } \\
\text { de soja }\end{array}$ & $\begin{array}{c}\text { Borra de } \\
\text { Soja }\end{array}$ & $\begin{array}{l}\text { Calcário } \\
\text { Calcítico }\end{array}$ & Sal comum \\
\hline MS & 90 & 88 & 87,5 & 56 & 100 & 100 \\
\hline MO & 92,03 & 98,84 & 93,54 & 100 & ----- & ----- \\
\hline $\mathrm{PB}$ & 10 & 8,1 & 46 & ----- & ----- & ----- \\
\hline $\mathrm{EE}$ & 2,3 & 3,6 & 1,5 & 56 & ----- & ----- \\
\hline FDN & 63 & 8,8 & 12,3 & ---- & ----- & ----- \\
\hline FDA & 39 & 2,9 & 8,2 & ----- & ----- & ----- \\
\hline CHT & 79,73 & 87,14 & 46,04 & ----- & ----- & ----- \\
\hline $\mathrm{CNE}$ & 16,73 & 78,14 & 33,74 & ----- & ----- & ----- \\
\hline CIN & 7,97 & 1,16 & 6,46 & ----- & ----- & ----- \\
\hline NDT & 54 & 80 & 78 & 155,02 & ----- & ----- \\
\hline $\mathrm{EL}^{1}$ & 1,20 & 1,84 & 1,79 & 3,68 & ----- & ----- \\
\hline $\mathrm{Ca}$ & 0,4 & 0,02 & 0,3 & ---- & 34 & ----- \\
\hline $\mathrm{P}$ & 0,27 & 0,21 & 0,69 & ----- & 0,02 & ----- \\
\hline
\end{tabular}

${ }^{1}$ Valor calculado segundo Moe e Tyrrel $(1976) \rightarrow$ EL $=(0,0245 \times$ \% NDT $)-0,12$.

Tabela 2. Proporção dos ingredientes (\%MS) e composição bromatológica das dietas experimentais

\begin{tabular}{|c|c|c|c|c|c|}
\hline & \multicolumn{5}{|c|}{ Teor de borra de soja } \\
\hline & 0 & 2,89 & 5,77 & 8,65 & 11,55 \\
\hline \multicolumn{6}{|c|}{ Proporção dos ingredientes (\%MS) } \\
\hline Feno de aveia & 40,00 & 40,00 & 40,00 & 40,00 & 40,00 \\
\hline Fubá de milho & 36,22 & 32,71 & 29,20 & 25,72 & 22,20 \\
\hline Farelo de soja & 21,88 & 22,50 & 23,12 & 23,73 & 24,35 \\
\hline Borra de soja & ---- & 2,89 & 5,77 & 8,65 & 11,55 \\
\hline Calcário calcítico & 0,90 & 0,90 & 0,90 & 0,90 & 0,90 \\
\hline Sal comum & 1,00 & 1,00 & 1,00 & 1,00 & 1,00 \\
\hline \multicolumn{6}{|c|}{ Composição bromatológica (\%MS) } \\
\hline $\mathrm{MS}$ & 88,89 & 87,47 & 86,12 & 84,85 & 83,63 \\
\hline MO & 93,08 & 93,08 & 93,08 & 93,08 & 93,08 \\
\hline PB & 17,00 & 17,00 & 17,00 & 17,00 & 17,00 \\
\hline $\mathrm{EE}$ & 2,55 & 4,05 & 5,55 & 7,05 & 8,55 \\
\hline FDN & 31,08 & 30,84 & 30,61 & 30,38 & 30,15 \\
\hline FDA & 18,44 & 18,39 & 18,34 & 18,29 & 18,24 \\
\hline CHT & 73,53 & 70,75 & 67,98 & 65,23 & 62,45 \\
\hline $\mathrm{CNE}$ & 42,38 & 39,84 & 37,31 & 34,80 & 32,26 \\
\hline CIN & 5,02 & 5,02 & 5,02 & 5,02 & 5,02 \\
\hline NDT & 67,64 & 69,80 & 71,94 & 74,10 & 76,26 \\
\hline EL & 1,54 & 1,59 & 1,64 & 1,70 & 1,75 \\
\hline $\mathrm{Ca}$ & 0,54 & 0,54 & 0,54 & 0,54 & 0,54 \\
\hline $\mathrm{P}$ & 0,3 & 0,3 & 0,3 & 0,3 & 0,3 \\
\hline
\end{tabular}

O alimento foi oferecido ad libitum, duas vezes ao dia, sendo os horários de arraçoamento às 7:30 e 17:30 horas. A quantidade oferecida foi ajustada em função da sobra observada diariamente, sendo que esta deveria ser de $15 \%$ da quantidade oferecida no dia anterior, de modo a garantir o consumo voluntário máximo dos animais. Nesse sentido, foram realizadas pesagens diárias das sobras e do alimento que foi oferecido pela manhã e pela tarde, para cada animal.

Durante o experimento, foram coletadas amostras dos alimentos fornecidos e das sobras, 
as quais foram identificadas e acondicionadas em freezer, para posteriores análises laboratoriais. Todas as amostras foram pré-secas em estufa ventilada a $65^{\circ} \mathrm{C}$ e, posteriormente, trituradas em moinho tipo Willey com peneira de $1 \mathrm{~mm}$. A seguir, foram acondicionadas em frascos identificados, sendo que posteriormente foram determinadas as concentrações de matéria seca (MS), matéria orgânica (MO), proteína bruta $(\mathrm{PB})$, extrato etéreo (EE), fibra em detergente neutro (FDN), fibra em detergente ácido (FDA) e cinzas (CIN), segundo metodologias descritas em Silva e Queiroz (2002). Todas as análises laboratoriais foram realizadas no Laboratório de Nutrição Animal da Universidade Federal de Santa Maria. Os carboidratos totais (CHT) dos alimentos fornecidos e das sobras foram calculados segundo Sniffen et al. (1992), em que $\mathrm{CHT}(\%)=100-(\% \mathrm{~PB}+\% \mathrm{EE}+\% \mathrm{CIN})$, e os carboidratos não estruturais (CNE), pela diferença de CHT - FDN. O consumo diário de nutrientes foi calculado pela diferença entre as quantidades ofertadas e os seus respectivos conteúdos nas sobras.

Os animais foram abatidos após um período experimental de 55 dias, precedido de um período de adaptação de 14 dias. Os abates foram realizados em abatedouro pertencente ao Departamento de Zootecnia da UFSM, localizado aproximadamente a 50 metros de distância do local do confinamento. O abate ocorreu após jejum de sólidos e líquidos de 14 horas, mediante insensibilização por atordoamento, seguido da secção das artérias carótidas e veias jugulares. Após cada abate, foi coletado todo o sangue e retirados pele, patas, cabeça, coração, rins, fígado, pulmões, baço, pênis, diafragma, pâncreas, gordura interna e gordura perirrenal, os quais foram pesados separadamente. Foram também pesados, individualmente, rúmen, retículo, omaso, abomaso, intestino delgado e intestino grosso, sendo esses órgãos pesados com conteúdo gastrintestinal. Logo após, foi realizado o esvaziamento e uma minuciosa lavagem dos diferentes compartimentos, os quais, após escorrimento da água, foram pesados novamente. Por diferença, obteve-se o peso do conteúdo de cada órgão constituinte do trato gastrintestinal. Em seguida, calculou-se individualmente a porcentagem dos diferentes órgãos internos em relação ao peso vivo dos animais.

As carcaças foram pesadas para determinação do peso de carcaça quente (PCQ) e rendimento de carcaça quente (RCQ), sendo, então, acondicionadas em câmara fria a $2^{\circ} \mathrm{C}$ por 24 horas. Após esse período, as carcaças foram novamente pesadas para obtenção do peso de carcaça fria (PCF), do rendimento de carcaça fria (RCF) e do índice de quebra ao resfriamento (IQ). A carcaça de cada animal foi separada em diferentes cortes comercias, segundo metodologia descrita em Osório et al. (1998).

Para realizar a análise econômica da alimentação oferecida no experimento, foram considerados os preços de mercado obtidos na região do estudo para os ingredientes das rações e peso vivo dos cordeiros. De posse do custo de cada ração e do seu consumo, foi calculado o resultado econômico proporcionado por ração. Consideraram-se os seguintes valores: $\mathrm{R} \$ 4,2 / \mathrm{kg}$ de peso vivo dos cordeiros, $\mathrm{R} \$ 0,30 / \mathrm{kg}$ de feno de aveia, R\$ 0,45/kg de milho moído, R \$ 0,90/kg de farelo de soja, $\mathrm{R} \$ 0,02 / \mathrm{kg}$ de calcário calcítico e $\mathrm{R} \$ 0,44 / \mathrm{kg}$ de sal. A receita do ganho de peso vivo (RGPV) foi obtida multiplicando-se o ganho de peso diário pelo preço pago por kg de peso vivo do cordeiro. O lucro do ganho de peso vivo (LGPV) foi obtido subtraindo-se o custo diário total com alimentação da RGPV obtida para cada cordeiro.

O delineamento experimental utilizado foi $\mathrm{o}$ inteiramente casualizado, com cinco tratamentos e cinco repetições. Os dados foram submetidos à análise de variância e foram testados os modelos de regressão linear, quadrática e cúbica, utilizando-se como critério para identificação do melhor modelo a significância dos coeficientes de regressão e o coeficiente de determinação. As análises foram realizadas utilizando-se o pacote estatístico SAS 9.1 (Statistical..., 2004), adotando-se o nível de significância de $5 \%$.

O presente trabalho faz parte do projeto aprovado pelo Comitê de Ética no Uso de Animais do Centro de Ciências Rurais da Universidade Federal de Santa Maria (CEUAUFSM), protocolo: 006. 


\section{RESULTADOS E DISCUSSÃO}

O aumento dos níveis de borra de soja da dieta ocasiona redução linear $(\mathrm{P}<0,01)$ do consumo de matéria seca, tendo como consequência o decréscimo linear no consumo dos demais nutrientes avaliados, com exceção do extrato etéreo, que aumentou linearmente (Tab. 3). O aumento verificado no consumo de extrato etéreo pode ser explicado pela elevação da concentração desse nutriente à medida que se eleva a proporção de borra de soja nas rações (Tab. 2). Já a redução verificada no consumo de matéria seca e de nutrientes pode ser atribuída à elevação do teor de extrato etéreo, pois, conforme Oliveira et al. (2009), o consumo e a digestibilidade podem ser afetados pelos níveis de lipídeos na dieta. Segundo Medeiros (2008), o valor crítico de teor de gordura na dieta estabelecido é de, no máximo, $6 \%$ de extrato etéreo na matéria seca, sendo que valores acima costumam reduzir a ingestão de matéria seca devido ao fato de que o maior teor de gordura plasmática sinalize ao sistema nervoso central que o animal não precisa ingerir mais, mecanismo de saciedade conhecido como quimiostático por envolver metabólitos sanguíneos. Além disso, os efeitos negativos em dietas com gordura acima do limite crítico ocorreriam pelo efeito tóxico direto dos ácidos graxos nos micro-organismos, e pelo efeito físico pelo recobrimento das partículas alimentares com gordura, com consequente redução do contato destas com agentes de digestão, sendo que o primeiro é considerado preponderante.

Lage et al. (2010) realizou um estudo avaliando a inclusão em níveis crescentes de glicerina bruta em substituição ao milho na terminação de cordeiros em confinamento, sendo que as dietas apresentavam teores de extrato etéreo de 3,04\%, $4,35 \%, 5,65 \%, 6,95 \%$ e $8,25 \%$. Os autores supracitados verificaram que o aumento do teor de extrato etéreo ocasionou a redução linear do consumo de nutrientes, corroborando os resultados obtidos no presente estudo. Da mesma forma, Santos et al. (2010), pesquisando níveis de $0 \%, 7 \%, 14 \%$ e $21 \%$ de farelo de arroz em substituição ao milho na ração concentrada para cordeiros da raça Santa Inês, o que proporcionou aumento da concentração de extrato etéreo nas dietas, verificaram redução linear para todas as variáveis de consumo analisadas, com exceção do extrato etéreo, resultado esse semelhantes aos obtidos neste estudo.

Tabela 3. Consumos médios de matéria seca (CMS), matéria orgânica (CMO), proteína bruta (CPB), extrato etéreo (CEE), fibra em detergente neutro (CFDN), carboidratos totais (CCHT), carboidratos não estruturais (CCNE) e de energia líquida (CEL), em função dos teores de borra de soja nas dietas experimentais

\begin{tabular}{|c|c|c|c|c|c|c|c|}
\hline & \multicolumn{5}{|c|}{ Teor de borra de soja } & \multirow{2}{*}{$\begin{array}{l}\text { Equação de } \\
\text { regressão }\end{array}$} & \multirow[b]{2}{*}{$\mathrm{P}>\mathrm{F}$} \\
\hline & 0 & 2,89 & 5,77 & 8,65 & 11,55 & & \\
\hline CMS, kg/dia & 1,206 & 1,072 & 0,884 & 0,848 & 0,802 & 1 & 0,0001 \\
\hline CMS, \% PV & 3,79 & 3,47 & 2,84 & 2,83 & 2,70 & 2 & 0,0004 \\
\hline CMS, g/kg PV ${ }^{0,75}$ & 89,81 & 81,69 & 67,01 & 66,10 & 63,06 & 3 & 0,0002 \\
\hline $\mathrm{CMO}, \mathrm{g} / \mathrm{kg} \mathrm{PV}^{0,75}$ & 82,78 & 75,08 & 61,57 & 60,84 & 58,04 & 4 & 0,0003 \\
\hline $\mathrm{CPB}, \mathrm{g} / \mathrm{kg} \mathrm{PV}^{0,75}$ & 17,20 & 15,83 & 12,94 & 12,97 & 11,98 & 5 & 0,0001 \\
\hline CEE, $\mathrm{g} / \mathrm{kg} \mathrm{PV}^{0,75}$ & 1,94 & 3,44 & 3,99 & 5,24 & 5,89 & 6 & 0,0001 \\
\hline CFDN, g/kg PV 0,75 & 26,40 & 18,92 & 15,54 & 14,43 & 14,85 & 7 & 0,0003 \\
\hline CCHT, $\mathrm{g} / \mathrm{kg} \mathrm{PV}^{0,75}$ & 63,69 & 54,62 & 42,65 & 39,60 & 36,42 & 8 & 0,0001 \\
\hline CCNE, g/kg PV ${ }^{0,75}$ & 37,84 & 36,37 & 27,64 & 25,66 & 22,05 & 9 & 0,0001 \\
\hline $\mathrm{CEL}, \mathrm{Mcal} / \mathrm{kg} \mathrm{PV}^{0,75}$ & 0,137 & 0,130 & 0,110 & 0,112 & 0,110 & 10 & 0,0093 \\
\hline
\end{tabular}

1. $\hat{\mathrm{Y}}=1,34357-0,06868 \mathrm{BS}, \mathrm{R}^{2}=0,52 ; 2 . \hat{\mathrm{Y}}=4,16262-0,18707 \mathrm{BS}, \mathrm{R}^{2}=0,43 ; 3 . \hat{\mathrm{Y}}=99,09206-4,60528 \mathrm{BS}, \mathrm{R}^{2}=$ 0,$45 ; 4 . \hat{Y}=91,23236-4,24693 B S, R^{2}=0,45 ; 5 . \hat{Y}=19,09888-0,88552 B S, R^{2}=0,50 ; 6 . \hat{Y}=0,51369+$ $0,64607 \mathrm{BS}, \mathrm{R}^{2}=0,85 ; 7$. $\hat{\mathrm{Y}}=28,2366-1,83901 \mathrm{BS}, \mathrm{R}^{2}=0,45 ; 8 . \hat{\mathrm{Y}}=73,13625-4,63803 \mathrm{BS}, \mathrm{R}^{2}=0,63 ; 9 . \hat{\mathrm{Y}}=$ $45,56244-2,81981 \mathrm{BS}, \mathrm{R}^{2}=0,67 ; 10 . \hat{\mathrm{Y}}=0,14693-0,00483 \mathrm{BS}, \mathrm{R}^{2}=0,26 ; \mathrm{BS}=$ Teor de borra de soja na dieta. 
Verifica-se que, embora tenha sido observada redução linear no ganho de peso diário, independentemente do teor de borra de soja testado, os cordeiros apresentaram ganhos de peso dentro de uma faixa de ganho que pode ser considerada satisfatória para a categoria animal avaliada (Tab. 4). Como consequência da redução do ganho de peso diário, houve também uma redução linear do peso vivo dos animais no momento do abate. Esse resultado pode ser explicado pela afirmativa de Gibb et al. (2005), de que a inclusão de gordura na dieta pode comprometer o desempenho animal devido à diminuição da taxa de degradação ruminal do alimento. Além disso, verificou-se no presente experimento que, à medida que se incrementou $o$ teor de borra de soja e, consequentemente, de extrato etéreo na dieta, os animais tenderam a selecionar o alimento, buscando principalmente uma maior ingestão do volumoso e menor de concentrado. Possivelmente isso ocorreu devido a uma redução da palatabilidade, uma vez que as dietas com altos teores de borra de soja apresentavam odor acentuado. Como consequência da redução do ganho de peso, observou-se redução do peso de carcaça quente e fria dos animais.

Tabela 4. Valores médios para peso vivo inicial (PVI), peso vivo ao abate (PVA), ganho de peso diário (GMD), conversão alimentar (CA), peso de carcaça quente (PCQ), peso de carcaça fria (PCF), rendimento de carcaça quente (RCQ), rendimento de carcaça fria (RCF), e para pesos e proporções de perna (PERN), paleta (PAL), costilhar (COST) e pescoço (PESC), em função dos teores de borra de soja nas dietas experimentais

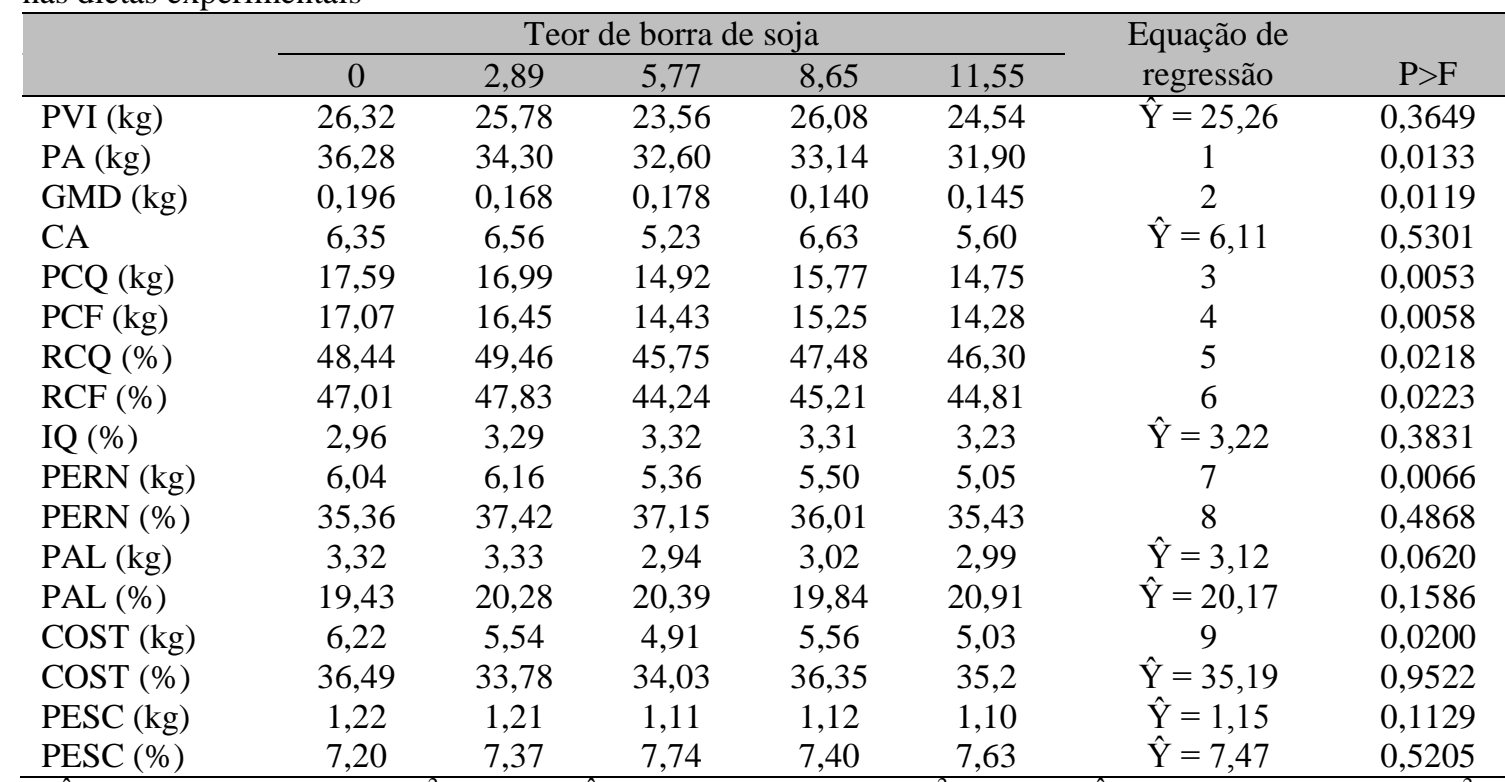

1. $\hat{\mathrm{Y}}=37,3144-0,66133 \mathrm{BS}, \mathrm{R}^{2}=0,84 ; 2 . \hat{\mathrm{Y}}=0,2141-0,00876 \mathrm{BS}, \mathrm{R}^{2}=0,78 ; 3 . \hat{\mathrm{Y}}=18,55678-0,4596 \mathrm{BS}, \mathrm{R}^{2}=$ 0,$76 ; 4$. $\hat{Y}=18,00004-0,45147 \mathrm{BS}, \mathrm{R}^{2}=0,76 ; 5$. $\hat{\mathrm{Y}}=49,79964-0,4168 \mathrm{BS}, \mathrm{R}^{2}=0,50 ; 6 . \hat{\mathrm{Y}}=48,29948-0,4216 \mathrm{BS}$, $\mathrm{R}^{2}=0,50 ; 7 . \hat{\mathrm{Y}}=6,59778-0,1756 \mathrm{BS}, \mathrm{R}^{2}=0,79 ; 8 . \hat{\mathrm{Y}}=31,61841+2,07939 \mathrm{BS}-0,19498 \mathrm{BS}^{2}, \mathrm{R}^{2}=0,37 ; 9 . \hat{\mathrm{Y}}=$ $6,32646-0,1572 \mathrm{BS}, \mathrm{R}^{2}=0,51$.

$\mathrm{BS}=$ Teor de borra de soja na dieta.

Com relação à diminuição verificada nos rendimentos de carcaça quente e fria, pode-se explicar esse resultado pela redução de digestibilidade da dieta com a elevação do teor de extrato etéreo, o que leva a uma redução da taxa de passagem e aumento da permanência do alimento sólido no rúmen dos animais, proporcionando diferentes proporções de conteúdo gastrintestinal no momento do abate
(Tab. 5) e, consequentemente, redução de rendimento.

Os pesos de perna e de costilhar, expressos em $\mathrm{kg}$, diminuíram linearmente com a elevação da borra de soja na dieta, sendo essa uma consequência da redução verificada no peso de carcaça fria. Com relação à porcentagem de perna, verificou-se comportamento quadrático. $\mathrm{O}$ 
máximo valor ocorreu no nível de $5,33 \%$ de borra de soja na dieta, correspondendo a uma proporção de perna de $37,16 \%$. Os valores médios obtidos para proporção dos diferentes cortes comerciais realizados na carcaça estão de acordo com Carvalho et al. (2005), os quais verificaram em cordeiros da raça Texel, abatidos aos 126 dias de idade, com peso vivo médio de $37,73 \mathrm{~kg}$, terminados em confinamento com dieta contendo $40 \%$ de feno de Tifton- 85 e $60 \%$ de concentrado, valores médios de $20,52 \%$ para paleta e 7,45\% para pescoço. Em outro estudo, Pereira et al. (2001) observaram em cordeiros da raça Corriedale, machos castrados, valores médios de $35,37 \%$ para perna, 20,19\% para paleta, $35,13 \%$ para costilhar e $8,58 \%$ para pescoço, resultados esses concordantes com os do presente estudo.
Na Tabela 5 estão apresentados os dados dos componentes não integrantes da carcaça de cordeiros alimentados com diferentes teores de borra de soja na dieta. As proporções de trato gastrintestinal e de rúmen, com conteúdo, e a de conteúdo gastrintestinal aumentaram linearmente com o aumento do nível de borra de soja na dieta. Esses resultados podem ser explicados pelo fato de que, ao se aumentar o teor de borra de soja, eleva-se o teor de extrato etéreo da dieta, podendo levar à diminuição da digestibilidade desta e, com isso, aumentar o tempo de permanência do alimento no rúmen e trato gastrintestinal, ocasionando uma maior proporção de conteúdo gastrintestinal.

Tabela 5. Valores médios, em \% (P), para sangue, pele, patas, cabeça, coração, rins, fígado, pulmão, baço, pênis, diafragma, pâncreas, gordura interna (Pgordi), gordura perirrenal (Pgordp), rúmen, retículo, omaso, abomaso, intestino delgado (Pintdelg), intestino grosso (Pintgros), trato gastrintestinal com conteúdo (Ptratgche), trato gastrintestinal sem conteúdo (Ptratgvaz) e conteúdo gastrintestinal (Pcontgast), em função dos teores de borra de soja nas dietas experimentais

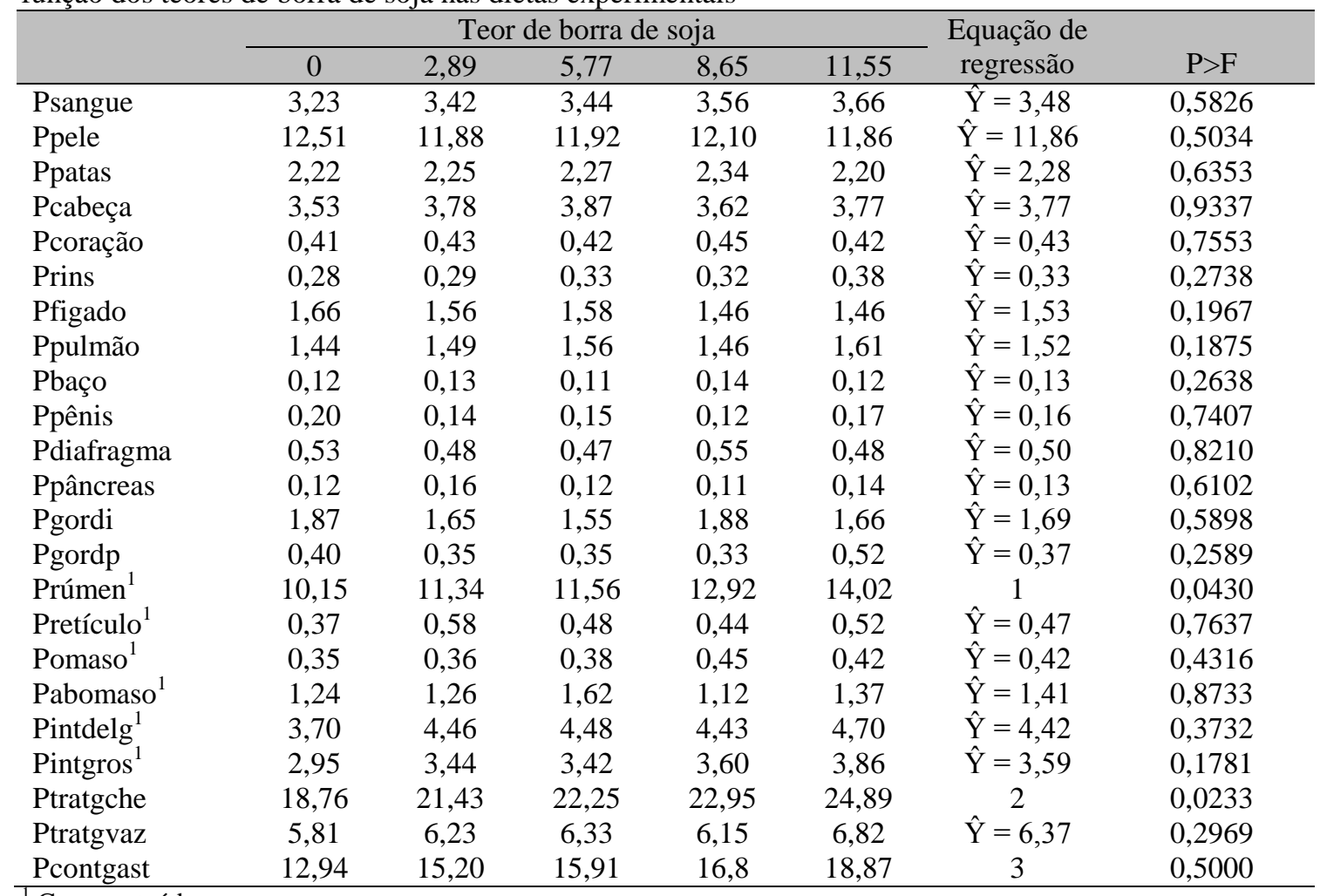

${ }^{1}$ Com conteúdo.

1. $\hat{Y}=9,51839+0,50639 B S, R^{2}=0,28 ; 2 . \hat{Y}=19,01776+0,63929 B S, R^{2}=0,34 ; 3 . \hat{Y}=13,32374+0,53071 B S, R^{2}$ $=0,26$.

$\mathrm{BS}=$ Teor de borra de soja na dieta. 
Os resultados referentes à análise econômica do experimento realizado são apresentados na Tabela 6. Na realização do cálculo, utilizou-se a quantidade oferecida de alimento e, portanto, foram consideradas as sobras. Com relação aos alimentos oferecidos, verifica-se que ocorreu uma redução linear no oferecido de matéria natural de feno e de concentrado, sendo essa uma consequência da redução do consumo de matéria seca dos animais (Tab. 3) à medida que aumentou o teor de borra de soja nas dietas. Esse aspecto fez com que o custo diário com feno e com concentrado e, consequentemente, o custo diário total com alimentação para cada animal também diminuíssem linearmente. Uma vez que o ganho de peso médio diário diminui linearmente com a elevação do teor de borra de soja na dieta, a receita do ganho de peso vivo também diminuiu. Contudo, observa-se que não houve diferença significativa em relação ao lucro do ganho de peso vivo, em $\mathrm{R} \$ /$ dia para cada animal, podendo-se inferir que a inclusão de borra de soja até o nível de $11,55 \%$ da matéria seca total da dieta é uma alternativa viável para a terminação de cordeiros em sistema de confinamento.

Tabela 6. Valores médios para custo do feno (CF), custo do concentrado $(\mathrm{CC})$, oferecido de matéria natural de feno (OMNF), oferecido de matéria natural de concentrado (OMNC), custo diário de feno (CDF), custo diário de concentrado (CDC), custo diário total (CDT), ganho de peso diário (GMD), receita do ganho de peso vivo (RGPV) e lucro do ganho de peso vivo (LGPV), em função dos teores de borra de soja nas dietas experimentais

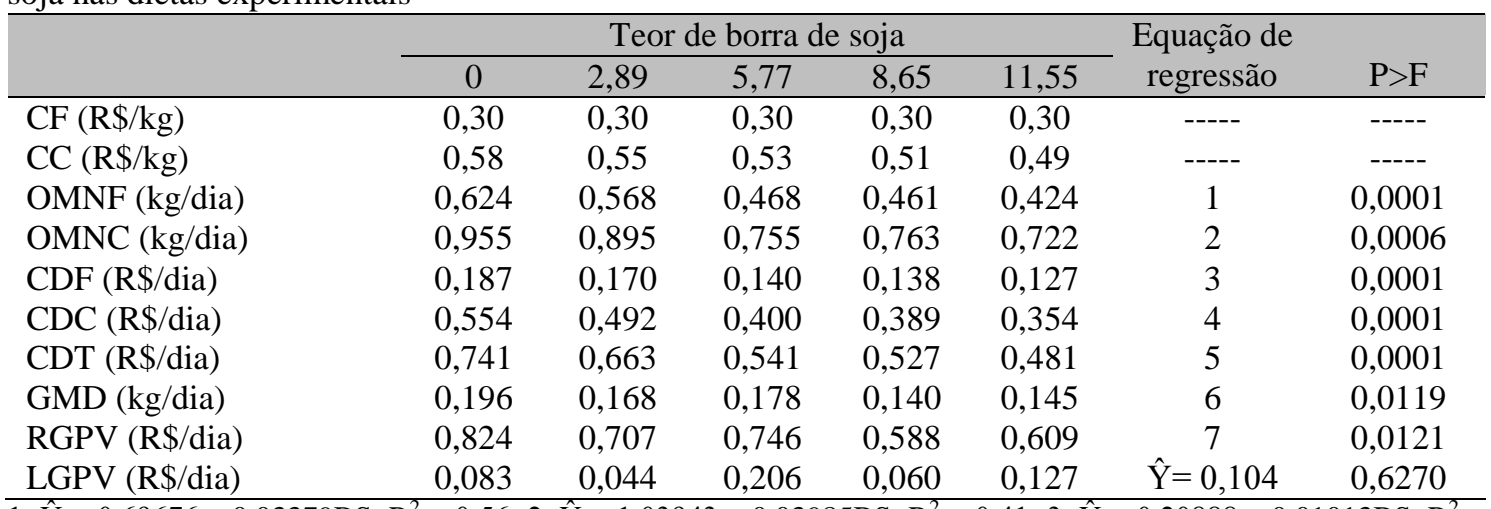

1. $\hat{Y}=0,69676-0,03379 B S, R^{2}=0,56 ; 2 . \hat{Y}=1,03943-0,03985 B S, R^{2}=0,41 ; 3 . \hat{Y}=0,20888-0,01013 B S, R^{2}=$ 0,$56 ; 4$. $\hat{Y}=0,62422-0,03355 B S, R^{2}=0,63 ; 5 . \hat{Y}=0,83310-0,04368 B S, R^{2}=0,61 ; 6 . \hat{Y}=0,2141-0,00876 B S$, $\mathrm{R}^{2}=0,78 . \hat{\mathrm{Y}}=0,89838-0,03667 \mathrm{BS}, \mathrm{R}^{2}=0,24$.

$\mathrm{BS}=$ Teor de borra de soja na dieta.

\section{CONCLUSÕES}

A utilização crescente de borra de soja na dieta de cordeiros em sistema de confinamento aumenta o teor de extrato etéreo nas dietas, tendo como consequência uma redução do consumo de matéria seca, ocasionando diminuição no ganho de peso. Além disso, há um aumento do conteúdo gastrintestinal no momento do abate, o que leva à redução do rendimento de carcaça dos animais. Contudo, o lucro diário obtido por animal não é influenciado, podendo-se inferir que a inclusão de borra de soja até o nível de $11,55 \%$ da matéria seca total da dieta é uma alternativa viável para a terminação de cordeiros em confinamento.

\section{REFERÊNCIAS}

BROCHIER, M.A.; CARVALHO, S. Consumo, ganho de peso e análise econômica da terminação de cordeiros em confinamento com dietas contendo diferentes proporções de resíduo úmido de cervejaria. Arq. Bras. Med. Vet. Zootec., v.60, p.1205-1212, 2008.

CARVALHO, S.; VERGUEIRO, A.; KIELING, R. et al. Desempenho e características da carcaça de cordeiros das raças Texel, Suffolk e cruza Texel x Suffolk. Cienc. Rural, v.35, p.11551160, 2005. 
GIBB, D.J.; SHAH, M.A.; MIR, P.S.; MCALLISTER, T.A. Effect of full-fat hemp seed on performance and tissue fatty acids of feedlot cattle. Canad. J. Anim. Sci., v.85, p.223230,2005

JOHNSON, R.R.; McLURE, K.E. High fat rations for ruminants. II. Effects of fat added to corn plant material prior to ensiling on digestibility and voluntary intake of the silage. $J$. Anim. Sci., v.36, p.397-406, 1973.

LAGE, J.F.; PAULINO, P.V.R.; PEREIRA, L.G.R. et al. Glicerina bruta na dieta de cordeiros terminados em confinamento. Pesq. Agrop. Bras., v.45, p.1012-1020, 2010.

MADRUGA, M.S.; SOUSA, W.H.; ROSALES, M.D. et al. Qualidade da carne de cordeiros Santa Inês terminados com diferentes dietas. Rev. Bras. Zootec., v.34, p.309-315, 2005.

MEDEIROS, S.R. Uso de lipídeos em dietas de ruminantes. Campo Grande: Maçal Nutrição Animal, 2008. 6p. (Pesquisa Embrapa)

MOE, P.W.; TYRREL, H.F. Estimating metabolizable and net energy of feeds. In: INTERNATIONAL SYMPOSIUM ON FEED COMPOSITION, ANIMAL NUTRIENT REQUIREMENTS, AND COMPUTERIZATION OF DIETS, 1976. Proceedings... Logan: Utah State University, 1976. p.232-237.

NATIONAL research council - NRC. Nutrient requirements of sheeps. Washington: National Academy Press, 1985. 99p.

NERES, M.A.; MONTEIRO, A.L.G.; GARCIA, C.A. et al. Forma física da ração e pesos de abate nas características de carcaça de cordeiros em creep feeding. Rev. Bras. Zootec., v.30, p.948954, 2001.
OLIVEIRA, R.L.; BAGALDO, A.R.; LADEIRA, M.M. et al. Fontes de lipídeos na dieta de búfalas lactantes: consumo, digestibilidade e N-uréico plasmático. Rev. Bras. Zootec., v.38, p.553-559, 2009.

OLIVEIRA, M.V.M.; PÉREZ, J.R.O.; ALVES, E.L. et al. Avaliação da composição de cortes comerciais, componentes corporais e órgãos internos de cordeiros confinados e alimentados com dejetos de suínos. Rev. Bras. Zootec., v.31, p.1459-1468, 2002. (suplemento).

OSÓRIO, J.C.S; OSÓRIO, M.T.M.; JARDIM, P.O. et al. Métodos para avaliação da produção de carne ovina, in vivo, na carcaça e na carne. 1.ed., Pelotas: Editora Universitária, 1998. 107p.

PEREIRA, P.S.; OSÓRIO, J.S.; MOREIRA, M. et al. Efeito da castração sobre a composição regional e tecidual em cordeiros Corriedale. Zootec. Trop., v.19, p.297-305, 2001.

SANTOS, J.W. dos; CABRAL, L.S.; ZERVOUDAKIS, J.T. et al. Farelo de arroz em dietas para ovinos. Rev. Bras. Saúde. Prod. Anim., v.11, p.193-201, 2010.

SILVA, D.J.; QUEIROZ, A.C. Análise de alimentos: métodos químicos e biológicos. 3.ed. Viçosa: UFV, 2002. 235p.

SNIFFEN, C.J.; O'CONNOR, J.D.; VAN SOEST, P.J. et al. A net carbohydrate and protein system for evaluating cattle diets; II. Carbohydrate and protein availability. J. Anim. Sci., v.70, p.3562-3577, 1992.

STATISTICAL Analysis System - SAS. User's Guide, version 9,1ed. North Caroline, SAS Institute INC., 2004. 5135p. 